\title{
Adoecer longe de casa: desafios psicossociais e coping
}

Teresa Ventura*

\section{RESUMO}

Introdução: A adaptação a um diagnóstico de cancro tem aspetos comuns a todos os doentes, não obstante o percurso individualizado de cada um. No presente caso ilustramos como os desafios colocados à doente foram moldados pelas suas circunstâncias específicas.

Descrição do caso: Mulher de 53 anos, empresária, natural e residente num país africano, a quem foi diagnosticado cancro da mama durante uma estadia em Portugal. A doença e as suas repercussões foram percebidas de forma muito negativa pela doente. A reação inicial foi claramente aversiva.

Longe de casa para se tratar, nunca se sentiu integrada (apesar de acompanhada por familiares). Experimentou dificuldades financeiras, agravadas pela instabilidade política no seu país de origem.

Com o decorrer do tempo ficou a conhecer melhor a doença, ultrapassou alguns desafios e adaptou-se às alterações na sua vida. Acabou por aceitar as suas novas circunstâncias, sendo capaz de projetar o seu futuro de forma construtiva.

Comentário: A distância geográfica entre os locais de residência e de tratamento aumenta as exigências psicossociais do adoecer. Este caso demonstra a adoção de uma variedade de estratégias de coping, em relação com avaliações e reavaliações das circunstâncias.

O coping tem múltiplas funções, incluindo a regulação emocional e a gestão dos problemas que causam distress. O coping permite, com base na resiliência pessoal, o controlo e resolução dos problemas ou a aceitação das circunstâncias quando a mudança não é possível. Este caso mostra como os desafios da doença podem ser ultrapassados, mesmo em situações difíceis.

O médico de família pode acompanhar a adaptação da pessoa à doença crónica e promover a sua funcionalidade. Isto implica gerir emoções, incluindo a modificação das emoções negativas da doente relativamente à doença.

Palavras-chave: Cancro; Acesso aos Serviços de Saúde; Impacto Psicossocial; Stress Psicológico; Adaptação Psicológica.

\section{INTRODUÇÃO}

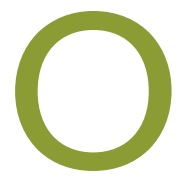

cancro da mama tem os níveis de incidência mais elevados na América do Norte e os mais baixos na Ásia e em África. ${ }^{1}$ De ocorrência rara nos homens, é o cancro mais frequente nas mulheres. ${ }^{2}$

Não obstante o percurso individualizado de cada doente, um diagnóstico de cancro tem exigências transversais, como a necessidade de integrar o controlo da doença nas atividades da vida diária, as expectativas do que pode acontecer se esse controlo não for conseguido e as emoções que evoca. ${ }^{3}$

O conhecimento de quais os processos do curso da vida, objetivos e relações pessoais que o cancro vem in-

*Assistente graduada sénior da USF (Unidade de Saúde Familiar) Santo Condestável; assistente convidada da Faculdade de Ciências Médicas da Universidade Nova de Lisboa; vogal do Conselho Regional do Sul da Ordem dos Médicos. terromper é importante para promover, junto a cada doente, o discernimento acerca dos problemas psicológicos que podem surgir em resposta à doença. ${ }^{4-5}$

Um ajustamento adequado pressupõe um processo de adaptação que não é instantâneo, mas que ocorre ao longo do tempo, em que o doente e a sua família vão aprendendo a lidar com as mudanças desencadeadas pela doença ${ }^{6} \mathrm{O}$ médico deve vigiar a resposta adaptativa à situação de doença de modo longitudinal e gerir oportunidades para favorecer um registo de funcionamento, pessoal e familiar, mais saudável.

O presente caso foi selecionado para apresentação por demonstrar:

- A distância geográfica entre o hospital em que a doente acede aos cuidados e o seu mundo habitual amplifica as repercussões da doença e aumenta os desafios psicossociais da adaptação requerida pela mesma; 
- A "ressignificação" da doença que ocorre ao longo do tempo;

- O uso de um grande repertório de estratégias de coping utilizadas para lidar com a situação, dependendo da (re)avaliação que a doente faz da situação, das suas emoções, dos recursos de que dispõe, bem como da interação entre esses fatores.

\section{DESCRIÇÃO DO CASO}

\section{Dados demográficos, antecedentes familiares e contexto onde se insere}

Gisela [nome fictício], 53 anos de idade, raça negra, católica, casada há 37 anos com Julião [nome fictício], tem nove anos de escolaridade e é empresária, gerindo um complexo turístico em África, no seu país natal e de residência habitual. Tem dois filhos, Bruno e Leonor [nomes fictícios] e três netos. Percebe a sua família como não tendo disfunções e considera-se o pilar desse bom funcionamento.

Bruno, 32 anos, casado, com um filho de 4 anos, trabalha na empresa dos pais. Leonor, 30 anos, recentemente divorciada, com dois filhos, de 8 e 2 anos respetivamente, frequenta um curso superior noutro país.

Gisela é a primeira filha de uma fratria de dez irmãos, sendo a única mulher. Os sete irmãos mais novos já faleceram, três em contexto de guerra, um por acidente de viação e os restantes devido a doenças infetocontagiosas. Os dois irmãos vivos são saudáveis.

Gisela considera ter tido um bom relacionamento com os progenitores, mas refere uma maior ligação com o pai, descrevendo-o como uma pessoa alegre e divertida. A mãe faleceu há doze anos, com 60 anos de idade, no decorrer de uma descompensação de diabetes tipo 2, e o pai teve morte súbita há cinco meses, com 76 anos.

Não existem antecedentes familiares de doença oncológica.

Desde há vários anos, Gisela passava o Verão em Portugal, fazendo-se acompanhar pelos netos, ficando todos hospedados em casa de familiares. Durante a estadia, por maior confiança nos serviços de saúde portugueses, recorria à consulta da médica de família, de nacionalidade portuguesa, em cuja lista de utentes a sua família está inscrita, para vigilância do crescimento e desenvolvimento das crianças, dos seus próprios problemas de saúde e para os procedimentos preventivos indicados nos seus género e grupo etário.

Habita atualmente na casa da prima que a costuma acolher em Portugal. Foi o diagnóstico de cancro da mama, noVerão de 2011, que a fez permanecer em Portugal. Assim, a estrutura nuclear da família da prima, casada e com duas filhas adolescentes, tornou-se alargada. Não obstante reconhecer o apoio que estes familiares lhe proporcionam, acompanhando-a inclusive nas suas idas ao hospital, Gisela preocupa-se com a interferência que a sua presença prolongada causa no dia-a-dia da família, na qual não se sente completamente integrada. Assim, sai diariamente, passeando e visitando outros familiares e amigos.

A estrutura familiar de Gisela já tinha sofrido alterações recentes devidas a algumas crises - o divórcio da filha há cerca de um ano e a subsequente decisão de retomar os estudos num país estrangeiro, no que foi encorajada pelos pais, que assumiram cuidar dos netos durante as ausências prolongadas da mãe.

Gisela viveu vários outros acontecimentos stressantes, não normativos, ao longo da vida, nomeadamente o processo de descolonização e independência, vários golpes de estado e guerra civil no país natal, com repercussões na qualidade de vida da população (insegurança percebida e períodos de escassez de alimentos e outros bens). O último golpe de estado ocorreu durante a permanência de Gisela em Portugal, por motivos de doença, tendo seguido à distância, com grande ansiedade e preocupação, os acontecimentos e as suas repercussões no quotidiano da sua família.

\section{História biomédica pregressa}

Gisela teve a menarca aos 11 anos e a menopausa aos 51 anos de idade, não tendo feito terapia hormonal de substituição.

Teve duas gestações, a primeira aos 21 anos de idade, e dois partos eutócicos. Amamentou ambos os filhos. Usou sempre métodos naturais como forma de contraceção.

Era sedentária. Fazia uma alimentação com três refeições diárias, ricas em gorduras saturadas e hidratos de carbono de absorção rápida. Não tinha hábitos tabágicos. Ingeria bebidas alcoólicas de forma esporádica, socialmente.

Tinha uma mamografia, datada de 2009, com resultado normal. 
Como problemas de saúde ativos apresentava: obesidade (índice de massa corporal de 34,7), que se acentuou após a menopausa; hipertensão arterial, controlada com dois fármacos, sem repercussões nos órgãos alvo; e gonartrose.

Não tinha antecedentes psiquiátricos.

\section{Processo de adaptação face ao diagnóstico e tratamento de cancro da mama}

Em 2011, dias após a sua chegada a Portugal, Gisela identificou uma massa palpável na mama direita. Recorreu à consulta da médica de família nesse mesmo dia, demonstrando medo e grande ansiedade. Foi-lhe dito que nem todas as massas mamárias são malignas e que só os exames complementares de diagnóstico poderiam esclarecer a natureza da lesão. Foram-lhe requisitadas mamografia e ecografia mamária.

Quinze dias depois, Gisela voltou à consulta para mostrar o resultado dos exames solicitados: mamografia BI-RADS 4 (anomalias suspeitas, segundo o sistema padronizado utilizado para uniformizar os relatos de mamografia - Breast Image Reporting and Data System); ecografia mamária revelando massa arredondada com $1,7 \mathrm{~cm}$ de diâmetro, heterogénea, mal definida e agrupamento de calcificações pleomórficas no quadrante supero-externo da mama esquerda. Assim, a doente foi referenciada a consulta de Senologia para caracterização histológica da lesão. Ao tentar transmitir a informação de que só o exame anatomopatológico daria o diagnóstico definitivo, a resposta de Gisela foi hostil, insinuando que não poderia confiar por ter alimentado esperança de resultado benigno após a última consulta e, afinal, o diagnóstico temido tinha saído reforçado com a mamografia. Apresentava choro fácil, grande angústia, sensação de injustiça por ter sido atingida pela doença, recusa de mutilação mamária, ressentimento por uma doença que lhe "apertava" o futuro, medo de morrer longe da família e de não poder criar os netos enquanto a filha estudava, denotando uma sensação de completa perda de controlo sobre a sua vida. Relatava fazer autopalpação de várias regiões corporais, múltiplas vezes ao dia, à procura de metástases ou para verificar a evolução nas dimensões da massa mamária.

Decorrido cerca de um mês, Gisela voltou novamente à consulta por impetigo num dedo da mão, que atribuía a metastização da doença. A caracterização histológica da lesão mamária confirmou o diagnóstico de cancro da mama. Evidenciava labilidade emocional e relatava insónia inicial e intermédia, anorexia, perda de peso (menos $3 \mathrm{~kg}$ no último mês), grande ansiedade, anedonia e pensamentos intrusivos sobre a doença e o futuro. Para além da revolta e do receio quanto ao desfecho da doença, da recusa da desfiguração que o tratamento da mesma implicaria, preocupavam-na muitos outros aspetos relacionados com os processos que o cancro vinha interromper - conjugais, profissionais, financeiros, mas principalmente, tendo de permanecer em Portugal, como iria poder continuar a assegurar a educação dos netos e permitir que a filha prosseguisse o seu projeto de vida. A magnitude do que a doença veio pôr em causa exacerbava as dificuldades de aceitação da doença, vivendo o que descreveu como "uma descida aos infernos"(sic), o que levou a médica da consulta de Senologia a referenciá-la a consulta de Psicologia e a prescrever-lhe alprazolam $(0,5 \mathrm{mg}$, duas a três vezes/dia). Nesta consulta esclareceu-se a natureza da lesão do dedo da mão, prescreveu-se a terapêutica indicada, tendo sido ainda promovida a verbalização de sentimentos e a caracterização de recursos, humanos e materiais, que poderia mobilizar para atenuar as consequências da sua ausência no país natal.

Dois meses passados, Gisela reapareceu na consulta, agora sorridente, referindo:

- No estudo para estadiamento da doença não tinham sido encontradas metástases, tendo a cirurgia sido marcada para daí a uma semana;

- Tinha viajado até ao seu país, onde contratou uma ama para tratar dos netos e verificou que o marido tinha assumido, competentemente, tarefas inerentes à educação dos netos e à gestão do negócio;

- O marido, os filhos e os netos falavam com ela, por via telefónica, todos os dias;

- Tinha aumentado a frequência com que ia à igreja sempre que se sentia mais ansiosa, entrava na igreja mais próxima e rezava, o que a acalmava;

- Reencontrou uma amiga, funcionária no hospital onde se está a tratar e com neoplasia mamária diagnosticada há dois anos, a quem atribuía um papel determinante no otimismo com que estava a encarar a evolução da doença; contou que esta amiga a acompanhava a todas as consultas, fazendo sentir-se mais 
segura no hospital, um mundo até agora para ela desconhecido; enviava-lhe, diariamente, várias mensagens telefónicas com palavras de encorajamento e de afeto; mostrou-lhe as mamas após reconstrução, afirmando serem mais bonitas do que quando era jovem;

- Tendo já tido alta da consulta de Psicologia Clínica, reconhecia também os benefícios da intervenção psicológica breve na recuperação do seu equilíbrio emocional;

- Tendo obtido a informação de que a obesidade tem vindo a ser associada a uma maior incidência de cancro da mama, estava determinada a fazer uma alimentação mais equilibrada, autoculpabilizando-se por não o ter feito desde sempre e, assim, ter contribuído para a sua situação atual;

- Continuava a tomar o ansiolítico prescrito pela médica hospitalar, não excedendo a posologia mínima prescrita; o sono e o apetite tinham-se normalizado e referia sentir-se mais tranquila.

Tendo a médica de família disponibilizado o telemóvel pessoal na fase de choque, aquando da identificação da doença, Gisela enviou-lhe uma mensagem, dias após a última consulta, que se transcreve: "A vida apresenta-nos milhares de pessoas e cada uma delas vem cumprir um papel. Todas elas ficam na nossa memória, muitas em nossas fotos, algumas nos nossos hábitos... Mas no nosso coração ficam aquelas que são realmente especiais. Tudo isto para lhe dizer que fui operada na sexta e que desde ontem já estou em casa, sentindo-me bastante melhor. Obrigada por tudo."

Gisela voltou à consulta cerca de quatro meses após mastectomia, exérese de gânglio sentinela e colocação de expansor de tecido, visando reconstrução mamária futura. O exame histológico foi compatível com carcinoma ductal invasivo, grau 2 (moderadamente diferenciado), com componente de carcinoma in situ (20\%). Estava a fazer quimioterapia, apresentando alopecia, sensação de ardor e descamação cutânea a nível das mãos, alterações do paladar, bem como episódios de náuseas e diarreia, tendo recorrido por duas vezes ao serviço de urgência por vómitos incoercíveis com consequente desidratação. Depois de cada curso de quimioterapia já conseguia prever os dias em que iria ter estes últimos sintomas. A nível laboratorial apresentava sinais de depressão medular, com anemia (10,6mg/dl de hemoglobina), leucopenia (2.582 leucócitos $/ \mathrm{mm}^{3}$ ) e trombocitopenia ( 85.000 plaquetas $/ \mathrm{mm}^{3}$ ). Usava peruca, que considerava ficar-lhe bem.

Confiante no resultado dos tratamentos, Gisela demonstrava espírito de luta em relação à doença, afirmando "vou vencer o braço de ferro com a doença" (sic).

Continuava a falar diariamente, por telefone, com os familiares mais significativos e recebia apoio de muitos amigos e familiares residentes em várias regiões de Portugal, que se deslocavam para a visitar ou que ela procurava. No entanto, continuava a considerar intrusiva a sua permanência em casa da prima. Vinha à consulta pedir um relatório médico necessário para candidatura a uma habitação social. Afirmava que, se conseguisse esse objetivo, os seus netos viriam viver com ela, em Portugal.

Economicamente, encontrava-se em dificuldades. A ocorrência recente de um golpe de estado no seu país paralisou a economia e o marido já não conseguia disponibilizar-lhe as mesmas quantias de dinheiro. Tinha a informação de que, após terminar esta série de sessões de quimioterapia, teria de ter consultas de reavaliação da doença em cada três meses, não tendo disponibilidade financeira para se deslocar entre os dois países várias vezes por ano.

Não apresentava sintomatologia compatível com o diagnóstico de depressão, embora referisse que, por vezes, "apetece-me fechar-me no quarto e gritar" (sic).

\section{COMENTÁRIO}

Gisela foi atingida por uma doença de baixa incidência na sua raça e na sua região de proveniência. Para além do género, idade, menarca precoce, obesidade, inatividade física e consumo excessivo de gorduras saturadas, não se verificam outros fatores de risco para cancro da mama na sua história clínica, sendo que é frágil a evidência da contribuição de alguns dos fatores mencionados para a incidência desta doença.

\section{Desafios psicossociais}

O diagnóstico de uma doença grave gera ruturas no estilo de vida e um stress agudo e severo.

No caso de Gisela, a distância do seu mundo habitual originou uma magnitude inusitada das mudanças exigidas pelo adoecer e ampliou as perdas inerentes à notícia da doença, condicionando uma reação inicial 
mais intensa do que é comum e complicando o processo de adaptação à doença.

Também a ocorrência de outros acontecimentos de vida, antes e depois do diagnóstico do cancro, contribuíram para níveis superiores de stress.

Associada à acumulação de stressores, a representação do cancro da mama, social e da própria doente constituiu-se como uma barreira que contribuiu para a empurrar para estratégias iniciais pouco adaptativas.

Num estudo coordenado por Villaverde Cabral, ${ }^{7} \mathrm{em}$ que foram inquiridos 1.221 portugueses, $63 \%$ afirmaram ter medo de vir a ter cancro, enquanto apenas 7,7\% apontaram as doenças cardiovasculares, apesar destas constituírem a principal causa de morte em Portugal. Estes resultados salientam a construção social que se faz do cancro, o que afeta as experiências de doença e as atitudes do doente e de quem com ele se relaciona. No caso do cancro da mama, a mulher sente-se particularmente atingida, com sentimentos de perda e ameaça à imagem corporal que toca a própria sexualidade. Burton e Watson, ${ }^{8}$ afirmam que a mama, sendo um símbolo de feminilidade e de atrativo sexual, também está ligada, através do aleitamento, ao princípio de vida. Assim, é a identidade da mulher que está em causa quando a doença e tratamentos atingem esta região corporal. O grau desta agressão dependerá, não só do tipo de relação que a mulher mantém com o seu corpo e da forma como encara a alteração física a que foi submetida, mas também do meio sociocultural onde se encontra inserida. $^{8}$

No caso de Gisela, as baixas incidência e prevalência da doença no seu país de residência habitual contribuíram para um maior desconhecimento e uma representação ainda mais negativa do cancro da mama. Também os efeitos adversos ao longo dos ciclos de quimioterapia se constituem como exigências que se têm de aprender a gerir, interferindo no modo como se vivencia a doença e podendo mesmo requerer cuidados urgentes, como ocorreu no caso de Gisela em dois episódios de vómitos incoercíveis. Contrariamente ao que muitas vezes acontece, reagiu relativamente bem à alopecia.

\section{Recursos pessoais}

Relativamente aos recursos da doente, são de salientar:
- A resiliência de Gisela, com traços de personalidade como a sociabilidade, a autoconfiança, o locus de controlo interno, a extroversão, o otimismo e a capacidade de sonhar e fazer projetos;

- O padrão de funcionamento da família prévio à doença, caracterizado pela sua coesão, grande adaptabilidade e comunicação adequada, o que tornou possível uma negociação importante para efetuar mudanças necessárias às novas circunstâncias;

- A experiência acumulada, da doente e da sua família, em gerir situações stressoras de forma adaptada;

- A qualidade das estruturas de suporte social da doente e do tipo de suporte prestado, não obstante não ter podido contar com a presença física das pessoas mais significativas, que apenas puderam apoiá-la através de telefonemas;

- A sua religião, que constituiu um importante recurso para lidar com o stress e com a adversidade;

- Os recursos materiais de que dispõe, apesar da sua quebra recente;

- A capacidade de procurar, obter e processar informação relativa ao tratamento e prognóstico da doença e à resolução dos problemas dela decorrentes.

\section{Coping}

O coping tem múltiplas funções, incluindo a regulação do distress e a gestão dos problemas que causam distress.

As estratégias de coping correspondem a atividades sobre as quais o indivíduo está alerta ou consciente, distinguindo-se, assim, dos mecanismos de defesa (inconscientes). ${ }^{9}$

O indivíduo pode usar diferentes tipos de estratégias de coping, em combinação ou sequencialmente, dependendo das características da situação, da avaliação que dela faz (dano, ameaça, desafio; modificável ou inalterável), dos recursos de que dispõe, bem como da interação entre esses fatores. ${ }^{10}$

Segundo o modelo de autorregulação do comportamento de doença de Leventhal, as respostas à doença seguem três etapas: interpretação, coping e ponderação. ${ }^{11-12}$

Na etapa da interpretação, ao ser confrontada com uma doença, a pessoa tenta dar sentido ao problema, de acordo com as suas cognições sobre o mesmo. Estas cognições organizam-se em várias dimensões (identi- 
dade, causa, duração, consequências e cura/controlo) e acompanham-se de mudanças no estado emocional.

As cognições da doença e o estado emocional influenciam a segunda etapa, em que a pessoa identifica e seleciona estratégias de coping que lhe permitam readquirir a homeostasia ameaçada ou perdida.

A terceira etapa envolve a ponderação/avaliação sobre as estratégias de coping utilizadas, de modo a adaptar-se à sua doença e respetivas consequências, mantendo a qualidade de vida possível.

A autorregulação implica que os processos envolvidos nas três etapas do modelo se inter-relacionem de um modo dinâmico, numa recursividade de retroações.

No caso de Gisela, as cognições iniciais da doença, sobretudo as relacionadas com a identidade (etiqueta estigmatizante), as consequências e a controlabilidade da doença, levaram-na a vivenciar o estímulo stressor como uma enorme ameaça. Com o decorrer do tempo, a representação inicial muito negativa da doença e das suas novas circunstâncias de vida foi sendo substituída por uma ressignificação mais positiva, sendo patente a evolução de ameaça a desafio. A diferença entre um estímulo stressor vivenciado como ameaça ou desafio é que a avaliação produz emoções diferentes. Ambas mobilizam estratégias de confronto; no entanto, no primeiro caso há dificuldades em lidar com a situação, que se acompanha de preocupação, medo e ansiedade, enquanto no segundo o indivíduo pensa poder superar a situação.

Perceção de doença e coping são processos paralelos que se estreitam e se influenciam, levando a evolução na perceção de doença à adoção de novas estratégias de coping e vice-versa. De modo simultâneo ou sequencial foram várias as estratégias de coping utilizadas por Gisela, que se sistematizam segundo a caraterização de Moos e Sahaefer: ${ }^{13}$

- Focalizadas na avaliação, como evitamento cognitivo, na fase de diagnóstico da doença; esforços mentais para tornar um evento aparentemente incontrolável numa série de eventos controláveis; e redefinição cognitiva;

- Focalizadas no problema, como procura de informação e apoio, bem como realização de ações de controlo/resolução de problemas, incluindo adesão ao plano terapêutico;

- Focalizadas nas emoções, como expressão de senti- mentos de revolta e desespero; monitorização obsessiva do corpo para se certificar não haver mais alterações, para além das identificadas; utilização de ansiolítico; refúgio noutras atividades, como passeios ou conversas com familiares e amigos; procura de conforto na religião; identificação e adoção do humor que a amiga utilizava como estratégia para lidar com a doença; autoculpabilização, relacionada com a obesidade; por fim, aceitação das coisas tal como estavam a acontecer.

Uma das estratégias utilizadas por Gisela, de recrutamento e uso de suporte social, poderá ser caracterizada como mista.

No processo de ponderação/reavaliação sucessiva da situação terão sido determinantes o conhecimento do estádio da sua doença e da possibilidade de reconstrução mamária, os recursos pessoais e sociais da doente e a avaliação que entretanto ela foi fazendo da adequação destes para fazer frente aos desafios, bem como o resultado das estratégias de coping utilizadas na resolução de problemas e na regulação das emoções.

O padrão de copingé considerado adaptativo se promove o crescimento e amadurecimento pessoais ou disfuncional se favorece o declínio psicológico e a deterioração. Esta avaliação tem de ter em atenção os propósitos que as estratégias de copingestão a servir e a duração da sua utilização - perturbações emocionais e de comportamento podem constituir fases evolutivas do processo de aceitação da doença, como evidenciou o caso da Gisela e, só no caso de instalação definitiva, serem considerados um padrão disfuncional.

\section{Estádios da reação psicológica}

No caminho percorrido por Gisela reconhecem-se as etapas de reação psicológica face a perdas estudadas por Kübler-Ross em doentes terminais (negação, cólera, negociação, depressão e aceitação). ${ }^{14}$ Muitas questões se põem ao longo de todas as fases, como evidencia o caso da doente:

\section{Negação}

Durante o processo de diagnóstico, a resistência à possibilidade de cancro levou a que a doente salientasse, no discurso da médica, a incerteza do diagnóstico para legitimar a sua negação. Esta, numa fase inicial, tem uma função adaptativa, servindo para controlar a absorção da informação traumática, só resultando num 
ajustamento mal-adaptativo se permanecer ao longo do tempo.

\section{Cólera}

Aquando da confirmação do diagnóstico, a doente dirigiu, embora de modo contido, alguma da sua zanga à médica, num mecanismo de defesa (deslocamento). A mensagem telefónica enviada após cirurgia mostra como a hostilidade demonstrada durante a consulta, em que veio mostrar o resultado da mamografia, correspondeu apenas a uma fase, natural no processo de aceitação da doença, com que o médico tem de saber lidar.

\section{Negociação}

A determinação da Gisela em alterar os seus hábitos alimentares integra-se na etapa de negociação, sendo, no entanto, de encorajar. Para além dos benefícios gerais, a perda de peso contribuirá para a melhoria de outros problemas de saúde, nomeadamente a hipertensão arterial e a gonartrose.

\section{Depressão}

Gisela apresentou, embora transitoriamente, sintomas depressivos e perturbações de ansiedade enquadráveis no contexto de uma reação emocional característica da fase de diagnóstico, que entretanto se atenuaram. Estes sintomas não poderão ser classificados de psicopatológicos, mas antes como parte integrante do esforço de adaptação à situação. Face a situações de stress ocorridas no seu passado, a doente demonstrou controlo emocional, com ausência de psicopatologia, certamente pelos recursos adequados, pessoais e sociais, que detém. No entanto, mesmo sendo expectável que a resposta à doença se processe em coerência com a sua história, é necessário estar atento a sinais de depressão de modo a assegurar, se for o caso, a sua deteção e tratamento precoces.

\section{Aceitação}

Gisela acabou por aceitar a doença e por se acomodar às alterações das circunstâncias da sua vida. Desenhou objetivos e aspirações nesse novo contexto, por fim assumido, evidenciados, por exemplo, no plano de que lhe seja atribuída uma habitação em Portugal.

\section{Considerações finais}

Bloom ${ }^{15}$ observa que, no final do tratamento oncológico, já não são necessárias tantas idas ao hospital, o contacto com os técnicos é mais esporádico, podendo a família e amigos percecionar que a doença pertence ao passado. O doente pode, então, sentir que o suporte social começou a diminuir, experimentando dificuldades em integrar essa quebra. Na ausência de oportunidade para falar com os familiares e amigos da Gisela, alertei-a antecipadamente para essa possibilidade.

As pessoas sob elevado nível de stress tendencialmente percebem a sua saúde de forma mais negativa, procurando ajuda para lidar com sintomas que provavelmente ignorariam noutras circunstâncias. Outras pessoas, pelo contrário, concentrando os seus esforços nas mudanças exigidas pelos acontecimentos de vida, ignoram os sintomas ou outras necessidades de saúde. É este o caso de Gisela, que passou a descurar os procedimentos de prevenção secundária relacionados com a hipertensão arterial. Numa fase de maior estabilidade da doença, espera-se que readquira a sua atitude pró-ativa relativamente a este tipo de cuidados, o que já lhe foi lembrado.

Wheis e Reiss ${ }^{16}$ alertam para o risco de existir um ajustamento psicológico pobre quando as exigências da doença são altas. Nestes casos é necessária a intervenção de terceiros, como a do médico, de modo a facilitar a ativação plena das competências da família. Não é bem essa a situação da Gisela. Ela mostrou-se, afinal, uma mulher resiliente que, tal como a sua família, possui as competências necessárias para resolver os seus problemas. Assim, para além do papel inicial no processo de diagnóstico da doença, a médica de família pôde circunscrever o seu papel ao dar "assistência em viagem" no que às repercussões do cancro da mama diz respeito.

\section{Concluindo:}

A distância dos serviços de saúde condiciona: a capacidade individual de obter os cuidados de que necessita; o número e a amplitude das mudanças exigidas pelo adoecer; o grau de preservação dos papéis desempenhados habitualmente; o suporte social efetivo de que o doente pode usufruir; os custos associados ao acesso, como desembolsos com transporte e com estadia longe de casa, tempo perdido no trabalho, quebra no rendimento, despesas acrescidas para contratar terceiros que assegurem tarefas domésticas que antes o próprio realizava e gastos com meios de comunicação.

A acumulação de stressores, decorrentes da ausência 
de proximidade entre locais da residência e de prestação de cuidados, bem como da ocorrência de outros acontecimentos de vida, influencia a avaliação da situação de doença. Esta é ainda mais negativa se a doença for estigmatizante e se o tratamento gerar desfiguração corporal e efeitos adversos que interferem com o bem-estar físico.

A pessoa vai conhecendo melhor a doença à medida que lida com ela, fazendo reavaliações sucessivas da mesma. As avaliações da situação de doença e o coping são processos intrinsecamente associados, evoluindo em paralelo ao longo do tempo, podendo a mesma pessoa usar uma grande variedade de estratégias, em combinação ou sequencialmente.

O médico de família tem uma relação de suporte prévia à doença e conhece o doente e o seu contexto biopsicossocial, pelo que está numa posição privilegiada para detetar problemas e favorecer a adaptação funcional ao longo do tempo. A sua intervenção deve ser sistémica e incluir a gestão de emoções do doente e as suas próprias.

\section{AGRADECIMENTOS}

Ao Prof. Doutor Manuel Gonçalves Pereira, pela leitura crítica sábia e incisa deste artigo que muito contribuiu para o seu aperfeiçoamento.

\section{REFERÊNCIAS BIBLIOGRÁFICAS}

1. Tyczynski JE, Bray F, Parkin D. Breast cancer in Europe. ENCR, European Network of Cancer Registries; 2002.

2. Parkin DM, Bray F, Ferlay J, Pisani P. Estimating the world cancer burden: Globocan 2000. Int J Cancer. 2001;94(2):153-6.

3. Pais-Ribeiro JL. Introdução à psicologia da saúde. Coimbra: Editora Quarteto; 2005. ISBN 9895580452989

4. Sammarco A. Psychosocial stages and quality of life of women with breast cancer. Cancer Nurs. 2001;24(4):272-7.

5. Rowland JH. Developmental stage and adaptation. In Holland JC, Rowland $\mathrm{JH}$, editors. Handbook of psycho-oncology: psychological care of the patient with cancer. New York: Oxford University Press; 1990. p. 25-43. ISBN 9780195068979

6. Brennan J. Adjustment to cancer: cancer or personal transition? Psychooncology. 2001;10(1):1-18.

7. Villaverde Cabral M. Saúde e doença em Portugal. Lisboa: Imprensa de Ciências Sociais; 2002. ISBN 9789726710844

8. Burton M, Watson M. Counselling people with cancer. Chichester: John Wiley; 1998. ISBN 0471978132

9. Gelder M, Gath D, Mayou A, Cowen P. Oxford textbook of psychiatry. Oxford: Oxford University Press; 1996.

10. Carver CS, Scheier MF, Weintraub JK. Assessing coping strategies: a theoretically based approach. J Pers Soc Psychol. 1989;56(2)267-83.

11. Moos RH, Schaeffer JA. The crisis of physical illness: an overview and conceptual approach. In Moos RH, editor. Coping with physical illness: new perspectives. New York: Plenum Press; 1984. p. 3-25. ISBN 9780306416811

12. Leventhal $H$, Meyer D, Nerenz D. The common sense model of ilness danger. In Rachman S, editor. Contributions to medical psychology. New York: Pergamon; 1980. p. 7-13. ISBN 9780080205113

13. Hagger MS, Orbell S. A meta-analytic review of the common-sense model of illness representations. Psychol Health. 2003;18(2):141-84.

14. Kübler-Ross E. On death and dying. New York: Macmillan Publishing; 1969.

15. Bloom J. The role of family support in cancer sontrol. In Baider L, Cooper C, De-Nour AK, editors. Cancer and the family. New York: John Wiley \& Sons; 2000. p. 55-71. ISBN 9780471958901

16. Wheis $K$, Reiss $D$. Family reorganization in response to cancer: a developmental perspective. In Baider L, Cooper C, De-Nour AK, editors. Cancer and the family. New York: John Wiley \& Sons; 2000. p. 3-29. ISBN 9780471958901

\section{CONFLITOS DE INTERESSE}

A autora declara não ter conflitos de interesse.

\section{ENDEREÇO PARA CORRESPONDÊNCIA}

Maria Teresa Fernandes Ventura

Rua Joaquim Quirino, $n^{\circ} 6,11^{\circ}$ Direito, Paço de Arcos, 2770-089, Oeiras.

E-mail: theresa.v@sapo.pt

Recebido em 07-10-2013

Aceite para publicação em 09-06-2014 


\section{ABSTRACT}

\section{ILLNESS FAR FROM HOME: PSYCHOSOCIAL CHALLENGES AND COPING}

Introduction: Adaptation to a diagnosis of cancer has aspects common to all patients, regardless of the path each individual takes. In this case, we show how the challenges faced by the patient were shaped by their specific circumstances.

Description of the case: A 53-year-old businesswoman from an African country was diagnosed with breast cancer during a visit to Portugal. The patient perceived the disease and its effects negatively. The initial reaction was clearly aversive.

She was far from home during treatment and never felt integrated despite the presence of relatives. She experienced economic difficulties, which were aggravated by political turmoil in her country of origin.

With time, she came to know the disease better, overcame some challenges, and became adjusted to the changes in her life. Finally she accepted her new circumstances and was able to plan her future constructively.

Comment: Geographical distance between home and the place of treatment increases the psychosocial demands of a disease. This case shows the adoption of a variety of coping strategies with assessment and reassessment of the circumstances.

Coping has multiple functions, including emotional regulation and management of problems that cause distress. Coping, based on personal resilience, allows for control and resolution of problems or acceptance of circumstances when change is not possible. This case shows how challenges of a disease can be overcome, even in difficult situations.

The general practitioner can follow the adaptation of the person to chronic disease and promote function. This involves managing emotions, including modification of the patient's negative emotions about the disease.

Keywords: Cancer; Health Services Accessibility; Psychosocial Impact; Stress, Psychological; Adaptation, Psychological. 